\title{
Prospecção fitoquímica e determinação do potencial antioxidante in vitro da Licania tomentosa (Benth.)
}

\section{Phytochemical prospecting and determination of in vitro antioxidant Página | 2099 potential of Tomentosa Licance (Benth.)}

\author{
Jonathan Augusto da Silva ${ }^{1}$; Julielle dos Santos Martins' ${ }^{2}$; \\ Maria Lúcia Vieira de Britto Paulino ${ }^{3}$; Anderson Soares de Almeida ${ }^{4}$; \\ Jessé Marques da Silva Junior Pavão ${ }^{5}$; Aldenir Feitosa dos Santos ${ }^{6}$
}

\author{
(1)ORCID: OOOO-0002-1294-7555; Graduando em Licenciatura em Química pelo Instituto Federal de Alagoas (IFAL) e Técnico em \\ Laboratório (Centro Universitário CESMAC); jonathan23augusto@gmail.com; \\ (2)ORCID: O000-0001-6069-636X; Graduanda em Medicina pelo CESMAC; \\ (s)ORCID: 0000-0002-6387-7702; Graduanda em Medicina pelo CESMAC; \\ (4)ORCID: 0000-0002-6208-2406; Mestrando em Ciências Farmacêuticas pela Universidade Federal de Sergipe (UFS); \\ ${ }^{(5)}$ ORCID: OOO0-OO02-5217-3857; Docente e pesquisador do CESMAC e membro do Programa de Pós-graduação em Análise de \\ Sistemas Ambientais (PPGASA) também pelo CESMAC. \\ ${ }^{(6)}$ ORCID: OOOO-O001-6049-9446; Docente da Universidade Estadual de Alagoas (UNEAL - Arapiraca) e membro do Programa de \\ Pós-graduação em Análise de Sistemas Ambientais (PPGASA) pelo CESMAC.
}

Todo o conteúdo expresso neste artigo é de inteira responsabilidade dos seus autores.

Recebido em: 29 de setembro de 2019; Aceito em: 22 de março de 2021; publicado em 31 de 05 de 2021. Copyright(C) Autor, 2021.

RESUMO: De nome científico Licania tomentosa (Benth.), a oiti pertence à família Chrysobalanaceae, que abrange 17 gêneros e aproximadamente 450 espécies arbustivas e arbóreas, espalhadas por regiões tropicais e subtropicais. O seu gênero, Licania, é predominantemente neotropical, composto por árvores de pequeno e grande porte, que estão amplamente distribuídas no globo, passando pelo México, Flórida, Antilhas, até o sul do Brasil (FEITOSA, XAVIER \& RANDAU, 2012). Na medicina popular a Oiti é utilizada no tratamento de diabetes (AGRA, FREITAS \& BARBOSA-FILHO, 2007), no entanto, ainda sem comprovação científica. Estudos desenvolvidos por Miranda e colaboradores (2002), a respeito da ação farmacológica, indica que a semente apresenta ação antiviral frente ao vírus herpes. Além disso, compostos isolados da folha e frutos indicam ação anticarcinogênica (FERNANDES et al., 2003) e também leishmanicida (RIBEIRO et al., 2014). Neste contex to, o presente trabalho objetiva determinar o potencial de neutralização de radicais livres (AAO\%) do extrato etanólico da folha da L. tomentosa, a partir do método de sequestro do radical DPPH, que consiste em avaliar quantitativamente a redução do DPPH a partir da alteração de cor - que passa de púrpura para amarelada - em função da concentração de antioxidantes nas amostras. Para tanto, foi realizada inicialmente uma prospeç̧ão fitoquímica qualitativa, que demostrou a presença de classes de compostos de grande importância farmacológica tais como taninos flobatênicos, flavonoides catequinas, esteróides e saponinas. O resultado o obtido mostra o ex trato folha da $L$. tomentosa é eficiente no sequestro do radical DPPH, apresentando uma AAO \% de 50\% (CE50\%) na concentração de 63,03 $\mu \mathrm{g} / \mathrm{mL}$. O que indica um potencial apenas cerca de duas vezes inferior ao potencial antioxidante do extrato padrão da $G$. biloba, que é bastante conhecida por tal característica. Nesse sentido, faz-se necessário mais estudos para elucidar a relação entre a atividade redutora e a concentração dos constituintes fenólicos de seu extrato, bem avaliação do seu potencial antioxidante por meio de outras metodologias. Agradecemos aos CESMAC pela disponibilidade de seus laboratórios para elaboração dos experimentos.

PALAVRAS-CHAVE: L. tomentosa, prospecção fitoquímica, DPPH, atividade antioxidante.

ABSTRACT: Scientific name Licance Tomentosa (Benth.), OITI belongs to the Chrysobalanaceae family, which covers 17 genera and approximately 450 shrub and tree species, scattered by tropical and subtropical regions. Its genre, Licance, is predominantly neotropical, composed of small and large trees, which are widely distributed on the globe, passing through Mexico, Florida, Antilles, to the south of Brazil (Feitosa, Xavier \& Randau, 2012). In popular medicine OITI is used in the treatment of diabetes (Agra, Freitas \& Barbosa-Filho, 2007), however, still without scientific proof. Studies developed by Miranda and employees (2002), regarding pharmacological action, indicates that the seed presents antiviral action against the herpes virus. In addition, isolated sheet compounds and fruits indicate anti -Chinogenic action (Fernandes et al., 2003) and also Leishmanicide (Ribeiro et al., 2014). In this context, the present work aims to determine the potential for free radicals (AAO\%) of the ethanolic extract of L. tomentosa sheet, from the DPPH radical sequestration method, which consists of quantitatively evaluating the reduction of DPPH from of the color change - which passes from purple to yellowish - according to the concentration of antioxidants in the samples. In order to do so, a qualitative phytochemical prospecting was initially performed, which demonstrated the presence of classes of compounds of great pharmacological importance such as flobatenic tannins, catechine flavonoids, steroids and saponins. The result obtained shows the L. tomentosa sheet extract is efficient in the DPPH radical kidnapping, presenting a\% of $50 \%(\mathrm{CE} 50 \%)$ at the concentration of $63.03 \mu \mathrm{g}$ / ml. Which indicates a potential only about twice as low as the antioxidant potential of the standard extract of G. biloba, which is well known for such characteristic. In this sense, more studies are necessary to elucidate the relationship between the reducing activity and the concentration of the phenolic constituents of its extract, well evaluation of its antioxidant potential thro ugh other methodologies. We thank Cesmac for the availability of their laboratories for the elaboration of the experiments.

KEYWORDS: L. tomentosa, phytochemical prospecting, dpph, antioxidant activity. 


\section{INTRODUÇÃO}

A busca pelo alívio de dores e cura de doenças proporcionou à humanidade uma descoberta revolucionária: a possibilidade de se usar plantas com fins medicinais. A luta pela sobrevivência em um território hostil, como a terra na Era Pré-histórica, levou os povos primitivos a desenvolverem conhecimento intuitivo para tratamento de injúrias ou doenças através do uso das plantas e ervas. Conhecimento este, que se perpetuou até a contemporaneidade (VIEGAS Jr, BOLZANI \& BARREIRO 2006; PEREIRA \& CARDOSO, 2012) e foi essencial, para inaugurar uma área científica que hoje conhecemos como Química dos Produtos Naturais, ou especificamente, Fitoquímica.

Por meio da Fitoquímica foi-se descobrindo, isolando e elucidando as estruturas moleculares das substâncias ativas, ou seja, provenientes do metabolismo secundário das plantas, que foram paulatinamente sendo introduzidas na terapêutica e sendo utilizadas na produção de medicamentos de origem natural, em alternativa aos medicamentos de origem puramente sintética.

Dentre estes metabólitos, apresenta-se com grande relevância aqueles que possuem atividade antioxidante, pois agem como substâncias inativadora ou redutora de radicais livres. O que é de grande valia, dado que a ação desequilibrada dos radicais livres dentro do organismo, em uma situação de estresse oxidativo, tem-se apresentado altamente prejudicial ao organismo humano, sendo associado a diversas doenças e injúrias celulares tais como alterações no DNA, na estrutura celular e também se encontra associada a casos de câncer, declínio do sistema imune, envelhecimento precoce, doenças cardiovasculares, diabetes mellitus tipo I, entre outras (SIKORA et al., 2008).

É conhecido que os compostos fenólicos e em especial os flavonoides, possuem alto potencial antioxidante incluindo o sequestro e neutralização dos radicais livres, assim como, atividade quelante de oxigênio tripleto e singleto, ou decompositora de peróxidos (HAMINIUK et al., 2012). Incluem-se no bojo, também compostos como Vitaminas (C, E, A), carotenoides e alguns polifenóis, que também podem ser obtidos por meio da alimentação. Sob essa perspectiva, o presente trabalho busca contribuir com a análise fitoquímica e determinação do potencial antioxidante da planta popularmente conhecida - especialmente na região nordeste -como oiti. 
De nome científico Licania tomentosa (Benth.), a oiti pertence à família Chrysobalanaceae, que abrange 17 gêneros e aproximadamente 450 espécies arbustivas e arbóreas, espalhadas por regiões tropicais e subtropicais. O seu gênero, Licania, é predominantemente neotropical, composto por árvores de pequeno e grande porte, que estão amplamente distribuídas no globo, passando pelo México, Flórida, Antilhas, até o sul do Brasil (FEITOSA, XAVIER \& RANDAU, 2012). O fato de ser bastante disponível em quase todo o território brasileiro, a torna um objeto favorável para estudos.

$\mathrm{Na}$ medicina popular a Oiti é utilizada no tratamento de diabetes (AGRA, FREITAS \& BARBOSA-FILHO, 2007), no entanto, ainda sem comprovação científica. Estudos desenvolvidos por Miranda e colaboradores (2002), a respeito da ação farmacológica, indica que a semente apresenta ação antiviral frente ao vírus herpes. Além disso, compostos isolados da folha e frutos indicam ação anticarcinogênica (FERNANDES et al., 2003) e também leishmanicida (RIBEIRO et al., 2014).

Sua ação terapêutica pode estar relacionada a presença de constituintes químicos e ação de antioxidantes presentes na espécie L. tomentosa. Dado que Pessoa et. al. (2016) identificou a presença de ácido gálico, catequina, ácido clorogênico, ácido cafeico, epicatequina, ácido elágico, rutina, quercetina, quercitrina e canferol em extratos etanólicos e em suas frações metanólicas, aquosas e clorofórmicas (MEDEIROS, 2018).

\section{OBJETIVO GERAL}

Determinar o potencial de neutralização de radicais livres do extrato etanólico da folha da L. tomentosa, a partir do método de sequestro do radical DPPH.

\section{Objetivos específicos}

- Obter material vegetal;

- Preparar extrato vegetal, por meio da técnica de maceração a frio;

- Realizar a secagem do material por meio de rotaevaporação;

- Realizar testes preliminares de prospecção fitoquímica; 
- Avaliar atividade antioxidante do extrato, em diferentes concentrações, por meio do método DPPH;

- Plotar resultados e determinar a atividade antioxidante do extrato e obter a curva de atividade antioxidante;

- Determinar EC50 - concentração efetiva.

\section{METODOLOGIA}

\section{Coleta e preparo do extrato etanólico}

A coleta das folhas da Licania tomentosa (Benth.) foi realizada na zona rural de Craíbas-AL, em uma propriedade particular. As folhas obtidas foram secas à $50^{\circ} \mathrm{C} \mathrm{em}$ estufa de secagem e pulverizado em seguida. Pesou-se 720 (setecentos e vinte) g do material pulverizado e o submeteu à maceração etanólica a frio, com filtração e reposição de solvente à cada 48 (quarenta e oito) horas. Procedeu-se com 7 (sete) macerações em dias alternados, totalizando 14 (quatorze) dias. O extrato filtrado foi concentrado em um evaporador rotativo, com temperatura controlada e limitada à $40^{\circ} \mathrm{C}$, obtendo-se assim, o extrato etanólico bruto.

\section{Prospecção Fitoquímica}

O extrato obtido, foi submetido à prospecção fitoquímica, para determinação dos metabólitos secundários presentes. A metodologia utilizada foi adaptada de Matos (2009), com o objetivo de realizar prospecção dos seguintes aleloquimicos: fenóis, taninos pirógalicos, taninos flobafênicos, antocianina e antocianidina, flavonas, flavonóis, xantonas, chalconas, auronas, flavononois, leucoantocianidinas, catequinas, flavononas, flavonois, xantonas, esteróides, triterpenóides e saponinas. É uma metodologia de execução simples, que se baseia na mudança de coloração ou formação de precipitados após adição de reagentes específicos.

Do extrato obtido, preparou-se $35 \mathrm{~mL}$ a partir de uma alíquota do extrato e separou para os bioensaios de prospecção fitoquímica. Esse volume foi dividido em sete 
SILVA, Jonathan Augusto da; MARTINS, Julielle dos Santos; PAULINO, Maria Lúcia Vieira de Britto; ALMEIDA, Anderson Soares de; PAVÃO, Jessé Marques da Silva Junior; SANTOS Aldenir Feitosa dos

porções de $3 \mathrm{~mL}$ em tubos de ensaio numerados e identificados. Uma porção de $10 \mathrm{~mL}$ do extrato foi separada para aquecimento até total evaporação do líquido em banhomaria, para ser usada em testes de esteróides e saponinas triterpênicas.

\section{Avaliação da atividade antioxidante pelo método DPPH}

O potencial de redução de radicais do extrato etanólico da oiti foi determinado pelo método fotocolorimétrico in vitro, que tem como princípio o sequestro de radicais livres e visa avaliar a capacidade que os compostos antioxidantes possuem de doar um próton ao radical DPPH (2,2-difenil-1- picril-hidrazil), de modo a formar estruturas de ressonância estáveis (SILVA et al, 2019). No teste, preparou-se uma solução estoque de concentração $1 \mathrm{mg} \cdot \mathrm{mL}^{-1}$ (ppm) e a partir desta preparou-se soluções com concentrações de 5, 10, 20, 30, 50, 60, 125 e $200 \mu \mathrm{g} \cdot \mathrm{mL}^{-1}$. Adicionou-se 1,0 mL de solução de DPPH $(0,3 \mathrm{mM})$ a $2,5 \mathrm{~mL}$ da solução estoque do extrato, em triplicata para cada concentração. Preparou-se o branco com a adição de $2,5 \mathrm{~mL}$ de extrato e $1 \mathrm{~mL}$ de etanol também em triplicata para cada concentração e preparou-se três tubos negativos com adição de 2,5 $\mathrm{mL}$ de etanol e $1 \mathrm{~mL}$ de DPPH. O material foi guardado protegido da luz e após 30 minutos, a leitura da absorbância foi realizada em espectrofotômetro a $518 \mathrm{~nm}$. O percentual de inibição do DPPH (ou a \% da atividade antioxidante) foi calculado pela seguinte equação (Fig.1). Na qual "AAO\%” é a atividade antioxidante; "ABSA” é o valor de absorbância da amostra; "ABSB" é o valor de absorbância do branco; e "ABSC" é o valor da absorbância do controle negativo.

$$
\mathrm{AAO} \%=100-\frac{(\mathrm{ABSA}-\mathrm{ABSB}) \cdot 100}{\mathrm{ABSC}}
$$

Fig.1: Equação para determinação da atividade antioxidante. 


\section{Determinação EC5o (Concentração efetiva)}

Os valores de $\mathrm{AAO} \%$ e das concentrações foram relacionados utilizando o

programa "Excel for Windows", a partir do qual o gráfico foi gerado e do qual também Página | 2104 foi obtida a equação da reta, sendo possível calcular o CE50 que expressa a concentração efetiva mínima em que um extrato possui a capacidade de reduzir em $50 \%$ o radical DPPH. Para calcular o CE50 utilizou-se a equação obtida pela regressão linear do gráfico: $\mathrm{y}=\mathrm{ax}+\mathrm{b}$, onde $\mathrm{Y}=50$ e $\mathrm{X}=\mathrm{CE} 50 \mu \mathrm{g} \cdot \mathrm{mL}^{-1}$.

\section{RESULTADOS E DISCUSSÕES}

\section{Prospecção fitoquímica do extrato alcoólico das folhas da L. tomentosa}

A prospecção fitoquímica preliminar do extrato etanólico das folhas da $L$. tomentosa (Benth.) revelou a presença de taninos flobatênicos, flavonoides das classes: flavonas, flavonóis, chalconas, flavononóis, flavanonas, que são grupos fenólicos mais importantes e diversificados entre os produtos de origem natural (SIMÕES et al., 2010). Encontrou-se também xantonas, auronas, catequinas, esteroides e saponinas (Quadro 1). Tais compostos são conhecidos por sua atividade farmacológica e podem apontar uma possível atividade biológica anti-inflamatória da L. tomentosa, por exemplo. Resultados semelhantes foram obtidos por Carminate (2015), constando a presença de saponinas, flavonóis e esteroides. O resultado, por outro lado, difere do obtido no presente trabalho, pois a autora aponta que identificou também a presença de fenóis, alcaloides, taninos, terpenos e cumarias, possivelmente devido ao fato de a autora utilizar metodologias específicas para tal. Também não foi identificada a presença dos triterpenos (ácidos betulínico, oleanólico e pomólico) que foram apontados no estudo de Fernandes et al (2003) como possuidores de atividade antitumoral contra linhagem de células leucêmicas. Acredita-se que devido ao solvente escolhido para isolar tais triterpenos, dado que o autor utilizou uso de metanol e purificou com uma fração de diclorometano. 
Quadro 1 - Prospecção dos constituintes fitoquímicos das folhas de L. tomentosa (Benth.)

\begin{tabular}{cc}
\hline Constituintes fitoquímicos & Presença ou Ausência* \\
\hline Fenóis & - \\
Taninos pirogálicos & - \\
Taninos flobatênicos & + \\
Antocianina e antocianidina & - \\
Flavonas, flavonóis e xantonas & + \\
Chalconas e auronas & + \\
Flavononóis & - \\
Leucoantocianidinas & + \\
Catequinas & + \\
Flavanonas & + \\
Esteroides & + \\
Saponinas & +
\end{tabular}

*O sinal (+) é indicativo da presença, já o (-), indicativo de ausência do constituinte químico.

\section{Avaliação da capacidade antioxidante pelo teste de captura do radical DPPH}

Com relação a avaliação quantitativa da capacidade antioxidante (AAO\%) pelo método DPPH, observou-se que o extrato etanólico de L. tomentosa apresentou potencial significativo de redução do radical DPPH, com atividade linear (Fig.2)

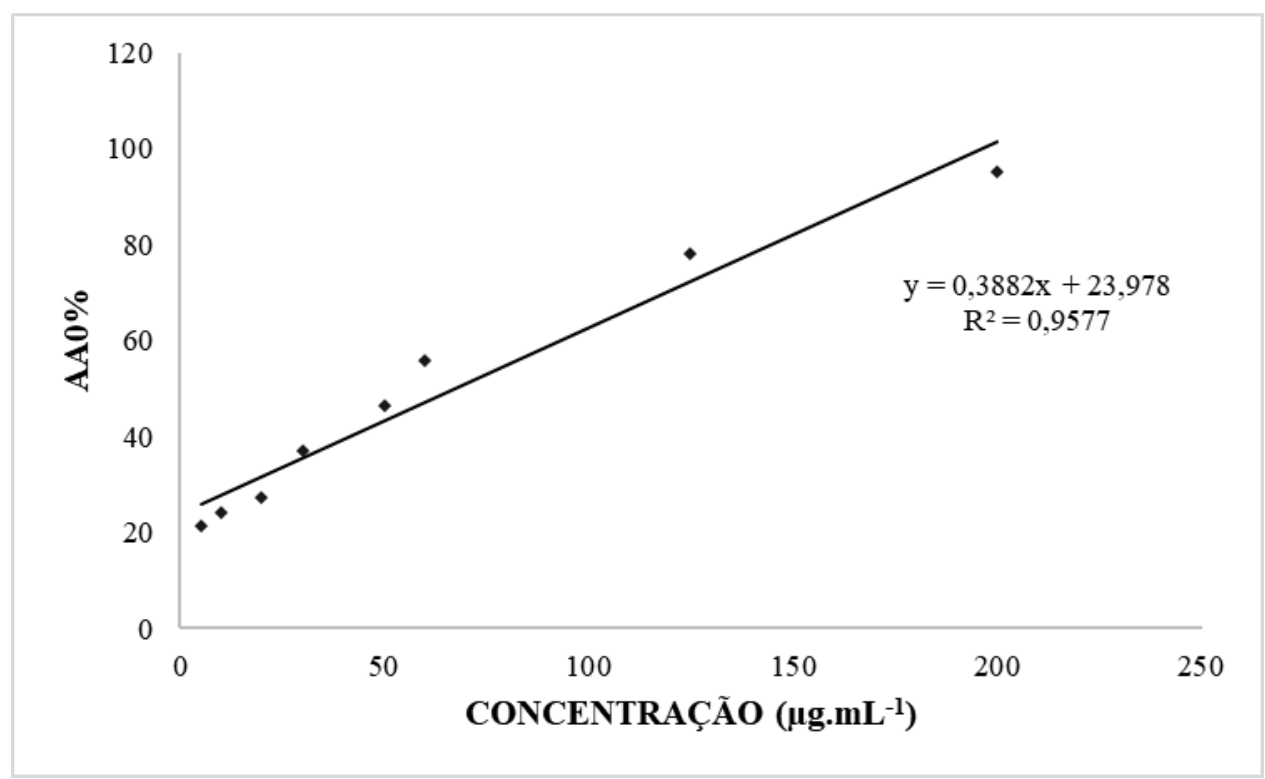

Fig. 2: AAO\% da fração da folha do extrato etanólico da L. tomentosa 
Observa-se que em concentração de $200 \mu \mathrm{g} \cdot \mathrm{mL}^{-1}$, o extrato apresentou o maior potencial de atividade (cerca de 95,21\%), enquanto que a concentração de $5 \mu \mathrm{g} \cdot \mathrm{mL}^{-1}$, apresentou o menor potencial $(21,40 \%)$, que pode estar relacionado à presença dos metabólitos secundários identificados em prospecção fotoquímica preliminar. O perfil Página | 2106 antioxidante da amostra pode ser demostrado por meio de uma equação linear, com reprodutibilidade estatista de cerca de $96 \%\left(\mathrm{R}^{2}=0,9577\right)$.

O extrato alcoólico da L. tomentosa, apresentou uma AAO\% de 50\% (CE50\%) na concentração de 67,03 $\mu \mathrm{g} \cdot \mathrm{mL}^{-1}$. Um parâmetro significativo e eficiente quando comparado ao potencial antioxidante da polpa do fruto da L. tomentosa que chega a uma CE50\% acima de $1.000 \mu \mathrm{g} / \mathrm{mL}$ (MEDEIROS, 2018), apesar de apresentar um potencial redutor inferior, pouco mais que seis vezes, ao potencial do extrato alcoólico das sementes do seu fruto em duas épocas diferentes (2015 e 2016), que possuem um CE50\% de $15,87 \pm 0,88 \mu \mathrm{g} / \mathrm{mL}$ e $10,30 \pm 0,15 \mu \mathrm{g} / \mathrm{mL}$, respectivamente (MEDEIROS, 2018). Além disso a L. tomentosa apresenta-se um potencial antioxidante apenas cerca de duas vezes menor que o do extrato padrão da Ginkgo biloba, cujo CE50\% é de 38,91 $\mu \mathrm{g} . \mathrm{mL}^{-1}$ (VICENTINO \& MENEZES, 2007) e é conhecida com uma das plantas com alta atividade antioxidante (MENSOR et al., 2001).

\section{CONCLUSÃO}

A análise fitoquímica do extrato da folha da L. tomentosa mostra que a suas folhas são ricas em fenóis, uma espécie química relacionada a diversas propriedades terapêuticas e farmacológicas. Os resultados apresentados, no que tange ao sequestro do radical DPPH pelas substâncias antioxidantes do extrato, sugerem que é possível que haja uma relação entre os compostos fenólicos presentes e sua atividade antioxidante, além disso, o $\mathrm{CE} 50 \%$, indica que a L. tomentosa é uma planta com um potencial redutor significativo, sendo apenas duas vezes menos potente que o extrato padrão de G. biloba. Nesse sentido, maiores estudos são necessários para elucidar a relação entre os compostos fenólicos e atividade antioxidante, além de outros a respeito de sua capacidade de neutralização de radicais livres por meio de outros métodos de determinação da atividade antioxidante. 


\section{AGRADECIMENTOS}

Agradecemos ao CESMAC pela disponibilização dos seus espaços laboratoriais Página | 2107 para o desenvolvimento das atividades de pesquisa, sem os quais não poderíamos elaborar o presente trabalho.

\section{REFERÊNCIAS}

1. AGRA, M. F.; FREITAS, P. F.; BARBOSA-FILHO, J.M. Synopsis of the plants know as medicinal and poisonouns in Northeast of Brasil. Revista Brasileira Farmacognosia. v. 17, p.114-140, 2007.

2. CARMINATE, B. Atividade de extratos etanólicos sobre o controle "in vitro” de Colletotrichum musae. 2015. Dissertação (Mestrado) - Universidade Federal do Espírito Santo, Espíriro Santo, 2015. Disponível em: $<$ http://repositorio.ufes.br/handle/10/8250>. Acesso em: 06 de jul. 2019.

3. FEITOSA, E. A.; XAVIER, H. S.; RANDAU, K. P. Chrysobalanaceae: traditional uses, phytochemistry and pharmacology. Rev. bras. farmacogn. v.22, ed.5, p.1181-1186, Set./Out. 2012.

4. FERNANDES, J. et al. Pentacyclic triterpenes from Chrysobalanaceae species: cytotoxicity on multidrug resistant and sensitive leukemia cell lines. Cancer Letters. v. 120, n.2, p. 165-169, 2003.

5. MATOS, F.J.A., 2009. Introdução à fitoquímica experimental. 3. ed. Fortaleza: Edições UFC.

6. MEDEIROS, J. L. de. Caracterização nutricional, atividade antioxidante e segurança de uso de frutos de OITI [Licania tomentosa (Benth.) Fritsch]. 2018. 106f. Tese (Doutorado em Bioquímica)-Universidade Federal do Ceará, Fortaleza, 2018.

7. MIRANDA, M. M. et al. Anti-herpes simplex vírus effect of a seed extract from tropical plant Licania tomentosa (Beth) Fritsch (Chrysobalanaceae). Phytomedicine. n.7 v.9, p. 641-645, 2002.

8. PEREIRA, R. J.; CARDOSO, M. G. Metabólitos secundários vegetais e benefícios antioxidantes. Journal of Biotechnology and Biodiversity. v. 3, n. 4, p. 146-152, Nov/2012.

9. PESSOA, I.P. et. al. Polyphenol Composition, Antioxidant Activity and Cytotoxicity of Seeds from Two Underexploited Wild Licania Species: L. rigida and L. tomentosa. Molecules. v. 21, n.12, p. 1-16, 2016. 
10. RIBEIRO, T.G. et al. Antileishmanial activity and cytotoxicity of Brazilian plants. Experimental Parasitology. v.143, p.60-68, 2014.

11. SILVA, F. R. G. et al. Phytochemical screening and in vitro antibacterial, antifungal, antioxidant and antitumor activities of the red propolis Alagoas. Braz. J. Biol., São Carlos , v. 79, n. 3, p. 452-459, Set. 2019.

12. SIMÕES, C. M. O. et al. Farmacognosia: da planta ao medicamento. Porto Alegre: UFRGS, 2010.

13. VIEGAS Jr, C.; BOLZANI, V. S.; BARREIRO, E. J. Os produtos naturais e a química medicinal moderna. Química Nova, v. 29, n. 2, p. 326-337, 2006.

14. SIKORA, E. et al. The antioxidant activity of selected cruciferous vegetables subjected to aquathermal processing. Food Chemistry, v.107, p.50-55, 2008.

15. MENSOR L. L. et al. Screnning of Brazilian plant extracts for antioxidant activity by the use of DPPH free radical method. Phytother Research. n.2, v.15, p.127-130, 2001.

16. VICENTINO, A. R. R.; MENEZES, F. de S. Atividade antioxidante de tinturas vegetais, vendidas em farmácias com manipulação e indicadas para diversos tipos de doenças pela metodologia DPPH. Revista Brasileira de Farmacognosia. Brazilian Journal of Pharmacognosy, v.17, n.3, p. 384-387, Jul./Set. 2007 